\title{
Basic characteristics of networks with self-similar traffic simulation
}

JEL: L62 DOI: 10.24136/atest.2019.023

Data zgłoszenia: 15.12.2018 Data akceptacji: 08.02.2019

This paper is devoted to simulations the networks with self-similar traffic. The self-similarity in the stochastic process is identified by calculation of the Herst parameter value. Based on the results, received from the experimental research of network perfomance, we may conclude that the observed traffic in real-time mode is selfsimilar by its nature. Given results may be used for the further investigation of network traffic and work on the existing models of network traffic (particularly for new networks concepts like loT, WSN, BYOD etc) from viewpoint of its cybersecurity. Furthermore, the adequacy of the description of real is achieved by complexifying the models, combining several models and integration of new parameters. Accordingly, for more complex models, there are higher computing abilities needed or longer time for the generation of traffic realization.

Keywords: traffic, network traffic models, fractal Brownian motion, selfsimiliarity, RMD-alhorythm.

\section{Admission}

The software tool Wireshark (earlier Ethereal) will be used in order to perform an experimental research of network performance. This is a tool for Ethernet packets analyzing and other networks (sniffer) with open source. The tool has a user graphic interface. The functionality, that is available with Wireshark, is very similar to the abilities of tcpdump tool, however the Wireshark has a praphic user interface and much more possibilities of sorting and filtering of information. The tool allows user to review all the traffic that flows in the network in the real-time mode, transferring it to a network map in promiscuous mode We consider the case of wireless network connection. For the experimental research, we use the network, the scheme of which is illustrated below:

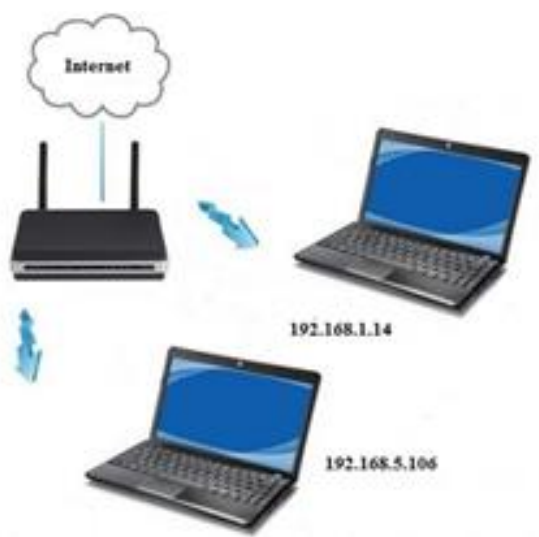

Fig. 1. The scheme of an experimental research network

The results of packets interception in the wireless network connection are displayed as:

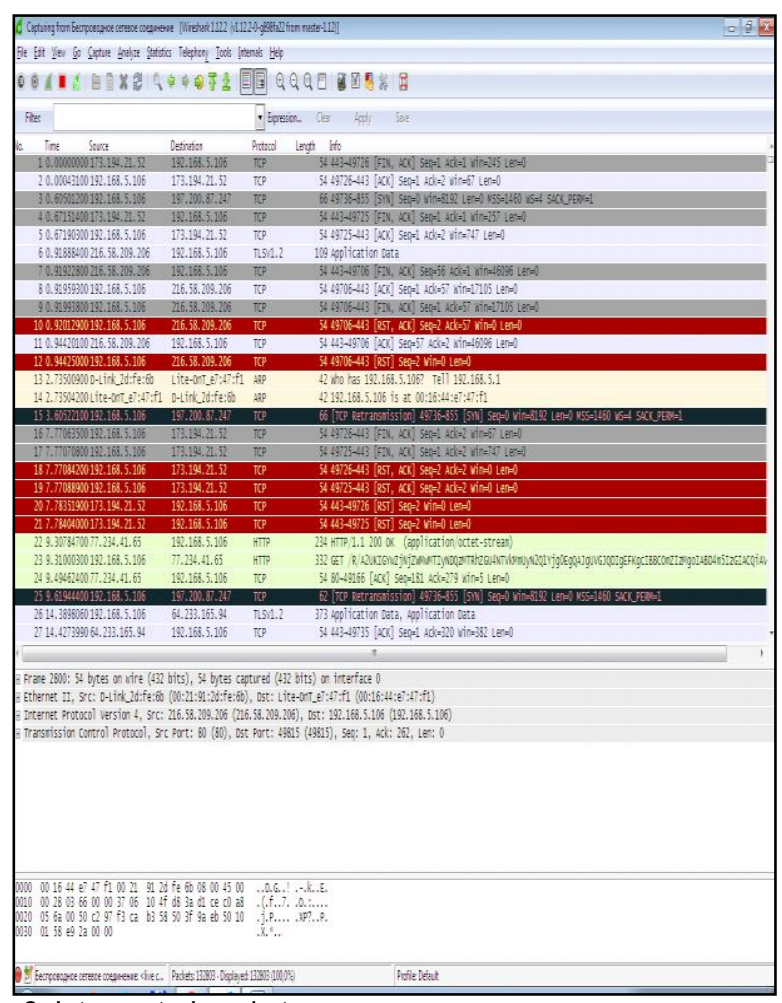

Fig. 2. Intercepted packets

It is possible to receive the graphical illustration of intercepted traffic for certain timeframe with the help of tool features, for instance:

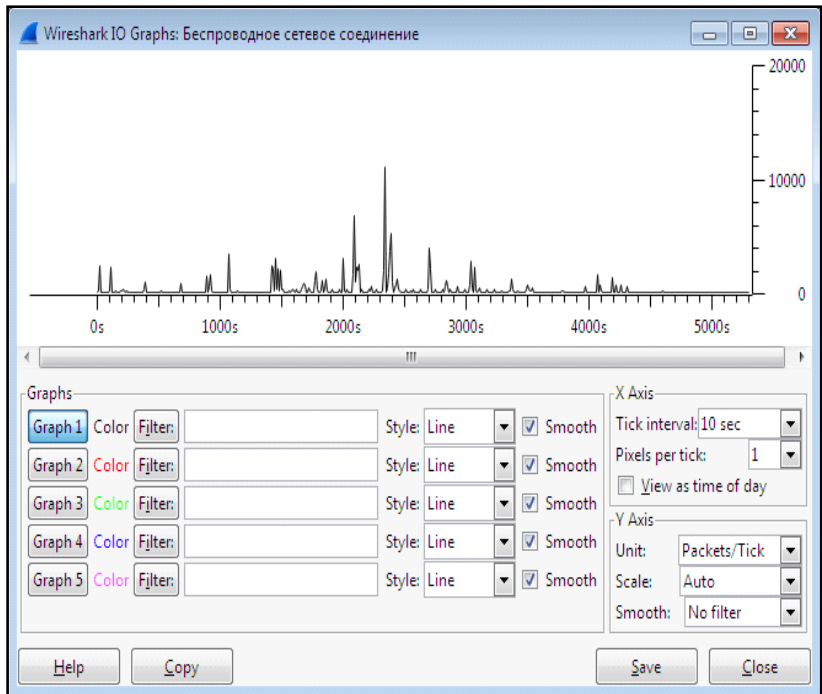

Fig. 3. The graphic illustration of intercepted traffic

There is a possibility of analyzing the percentage of different protocols after analysis of received data. The following steps are needed to get the access to hierarchical statystics: Launching the Wireshark $\rightarrow$ Wireless network connection $\rightarrow$ Start $\rightarrow$ Statistics $\rightarrow$ Protocol Hierarchy. 


\begin{tabular}{|c|c|c|c|c|c|}
\hline 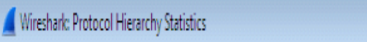 & & & & & $5 \sqrt{x}$ \\
\hline & Disply fiter: & & & & \\
\hline Protocol & Ypoockets & 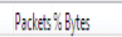 & Bjtes Mbits: & Proctes Eno bite En: & Enol Mbits : . \\
\hline A Frme & $1000 \%$ & ]13256 100,00\% & 95000080,0155 & 00 & $0,0,0$ \\
\hline 8 Ethenet & $10000 \%$ & $1 3 2 0 5 6 \longdiv { 1 0 0 , 0 0 \% }$ & 195000080 0155 & 00 & 0,000 \\
\hline B hitent Protocoll Vesion 4 & $980,0 \%$ & J1314999 $90711 \%$ & $0.55271310,0155$ & $0 \quad 0$ & 0,000 \\
\hline Q Trensmisision Control Protocol & $9624 \%$ & $\int 127956 \quad 90,06 \%$ & \$990557 0.154 & 976997023392 & 0,114 \\
\hline B Secure Socketes Lajer & $\sqrt{1534 \%}$ & 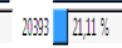 & $=020239940,0,33$ & 18662101055371 & 0,000 \\
\hline G Secure Sockets Lajer & $1,29 \%$ & $1 7 1 1 \longdiv { 2 6 8 \% }$ & 21605230,004 & 1775255599 & 0,004 \\
\hline Mallomed Pocket & $0,00 \%$ & $6 \longdiv { 0 , 0 1 \% }$ & $80340,0,000$ & 68934 & 0,000 \\
\hline B H.jpeted Transerer Protocol & $471 \%$ & $6 6 6 0 \longdiv { 4 . 1 4 \% }$ & - 3301780,0066 & 35232001554 & 0,003 \\
\hline Melid Jjpe & $0,22 \%$ & $2 5 \longdiv { 0 , 2 5 \% }$ & 2302040,000 & 205238024 & 0,000 \\
\hline ettensible Narlup language & $0,02 \%$ & $3 2 \longdiv { 0 , 0 2 \% }$ & 239000,000 & $32 \quad 23930$ & 0,000 \\
\hline Line-based tat dota & $0,64 \%$ & $8 5 5 \longdiv { 0 , 6 4 \% }$ & 6127330,001 & 855661273 & $0,001 \equiv$ \\
\hline 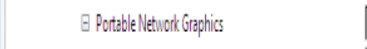 & $0,15 \%$ & $20601,0 \%$ & $15140,0,000$ & 204155241 & 0,000 \\
\hline Matomese Prockt & $0,00 \%$ & 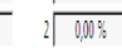 & 18990,000 & 21809 & 0,000 \\
\hline JPEG Gilentechange Fomit & $0,41 \%$ & $5 3 3 \longdiv { 0 . 4 \% }$ & 470180,0012 & $513 \quad 470018$ & 0,001 \\
\hline Compusene Gif & $0,41 \%$ & $5 0 0 \longdiv { 0 , 2 7 \% }$ & 263570,0000 & 540 263257 & 0,000 \\
\hline HTML Form URL Encoded & $0,01 \%$ & $9 \longdiv { 0 , 0 1 \% }$ & 930150,000 & 99975 & 0,000 \\
\hline 日 anascript Object Intation & $0.13 \%$ & $1 7 1 \longdiv { 0 , 1 1 \% }$ & 106930,0000 & 806758 & 0,000 \\
\hline Line-bosed teet data & $0,07 \%$ & $9 1 \longdiv { 0 , 0 4 \% }$ & 39650,0000 & 9139665 & 0,000 \\
\hline Maffomed Packet & $0,01 \%$ & $1 3 \longdiv { 0 , 0 1 \% }$ & 56060,0000 & 135661 & 0,000 \\
\hline Onine Certificate Sitatus Protocol & $0,06 \%$ & $7 8 \longdiv { 0 , 0 5 \% }$ & 49020,000 & $78 \quad 4902$ & 0,000 \\
\hline 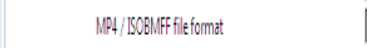 & $0,00 \%$ & $1 \longdiv { 0 , 0 0 \% }$ & 760.0000 & 1761 & $0,0000^{-}$ \\
\hline Mallomel Pocket & 0399 & $5 1 8 \longdiv { 0 , 2 5 \% }$ & 238180,000 & 518233318 & 0,000 \\
\hline Data & $2112 \%$ & $2 8 5 \longdiv { 0 , 1 6 \% }$ & 1537500,000 & 2825155375 & 0,000 \\
\hline Q NeEBOS Session Senice & $0,18 \%$ & $2390,0,04 \%$ & $40,040,0,000$ & $28 \quad 2576$ & 0,000 \\
\hline a SMB (Sener Messge Block Protocol) & $0,09 \%$ & $1 2 0 \longdiv { 0 , 0 2 \% }$ & $23,340,000$ & $92 \quad 16312$ & 0,000 \\
\hline ESMBPpipe Protocol & $0,02 \%$ & $2 8 \longdiv { 0 , 0 1 \% }$ & 50320,000 & $0 \quad 0$ & 0,000 \\
\hline 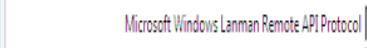 & $0,02 \%$ & $2 8 \longdiv { 0 , 0 1 \% }$ & 50320,000 & $28 \quad 5032$ & 0,000 \\
\hline 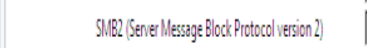 & $0,07 \%$ & $9 1 \longdiv { 0 , 0 2 \% }$ & 170240,000 & $91 \quad 17024$ & 0,000 \\
\hline Websocket & $0,01 \%$ & $1 6 \longdiv { 0 , 0 1 \% }$ & 8760,0000 & $16 \quad 8576$ & 0,000 \\
\hline 8 User Dotagyem Protocol & $260 \%$ & $3 5 1 \longdiv { 0 , 6 6 4 \% }$ & 617080,0001 & 00 & 0,000 \\
\hline Domain Name Serice & $1.89 \%$ & $2 5 0 \longdiv { 0 , 4 3 \% }$ & 41:18370,001 & 25094.1187 & 0,001 \\
\hline Booststap Protocol & $0,04 \%$ & $5 3 \longdiv { 0 , 0 2 \% }$ & 26510,000 & 5322651 & 0,000 \\
\hline NetBOSS Name Senice & $0,66 \%$ & $6 0 8 \longdiv { 0 , 0 6 \% }$ & 502000000 & 60856090 & 0,000 \\
\hline 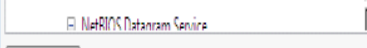 & nח)\% & 3ी & TAR A n & $1 \quad 1$ & $\mathrm{~nm} \mathrm{~m}^{\circ}$ \\
\hline Hep & & & & & Sloset \\
\hline
\end{tabular}

Fig. 4. Hierarchy of protocols

With the help of a packet length filter (Lauching Wireshark $\rightarrow$ Wireless network connection $\rightarrow$ Start $\rightarrow$ Statistics $\rightarrow$ Packet Lengths) we receive the quantity of packets of various duration, their percentage, range of minimum and maximum values of packets etc.

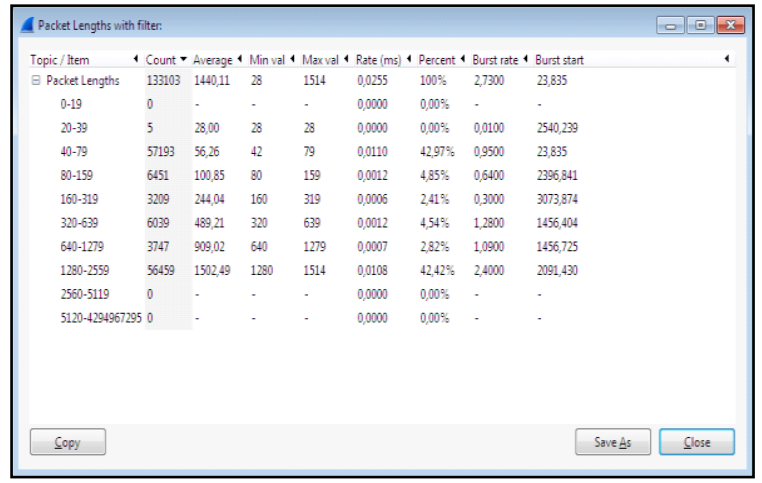

Fig. 5 The results of packets filtering by length
The general information about the interseption session, meaning its beginning, end, amount of packets, average transmission speed is displayed in Comments Summary.

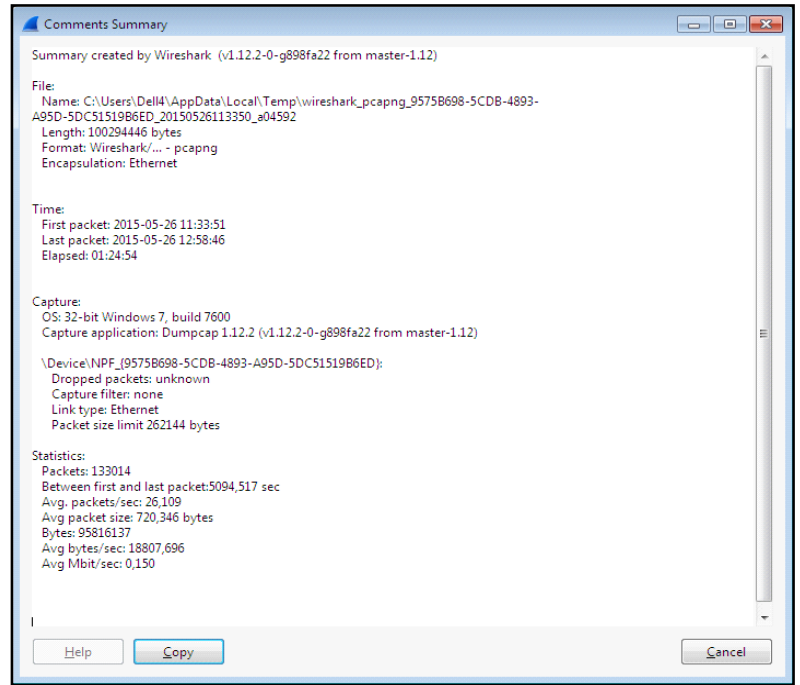

Fig. 6. The general information about interception session

Now we consider one more case of traffic interseption in wireless network connection. The results of packets interseption in the wireless network connection are displayed as follows:

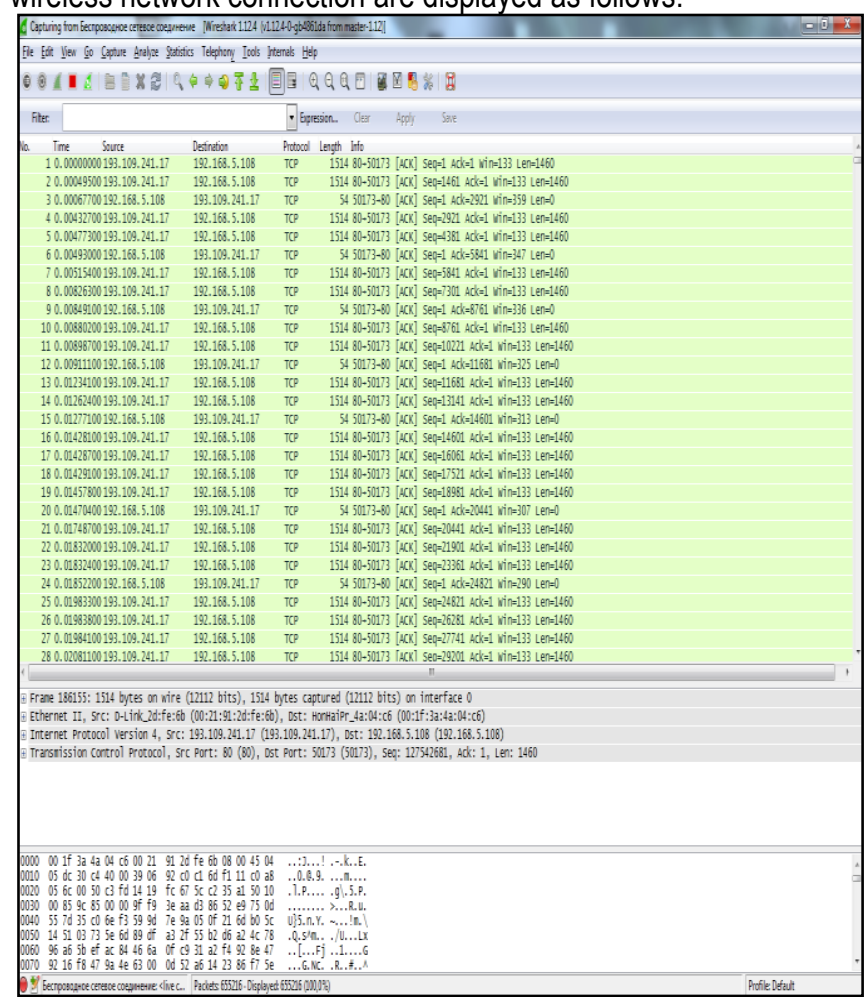

Fig. 7. Intercepted packets

With the help of tool features, it is possible to get the graphical illustration of intersepted traffic for certain timeframe, for instance: 


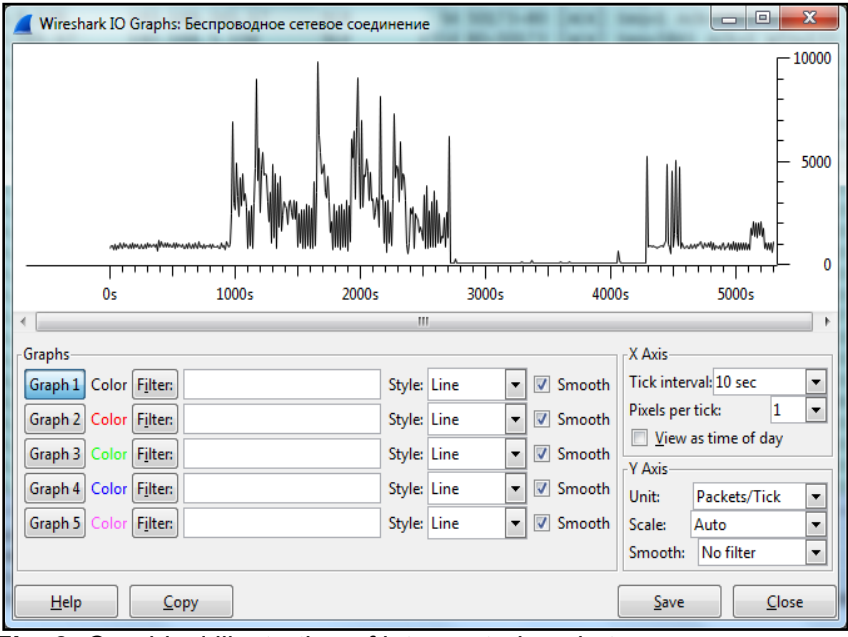

Fig. 8. Graphical illustration of intersepted packets

We now analyze the received data with the help of protocols hierarchy statistics.

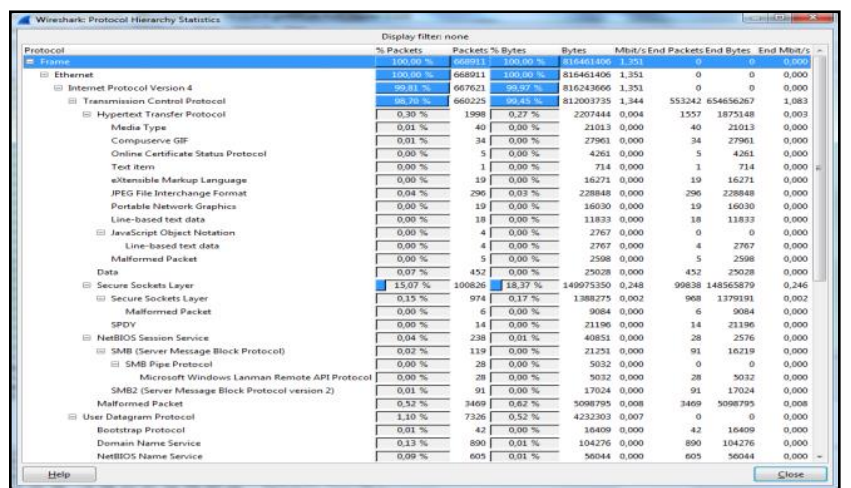

Fig. 9. Protocol hierarchy

With the help of a packet length filter we receive the quantity of packets of various duration, their percentage, range of minimum and maximum values of packets, etc.

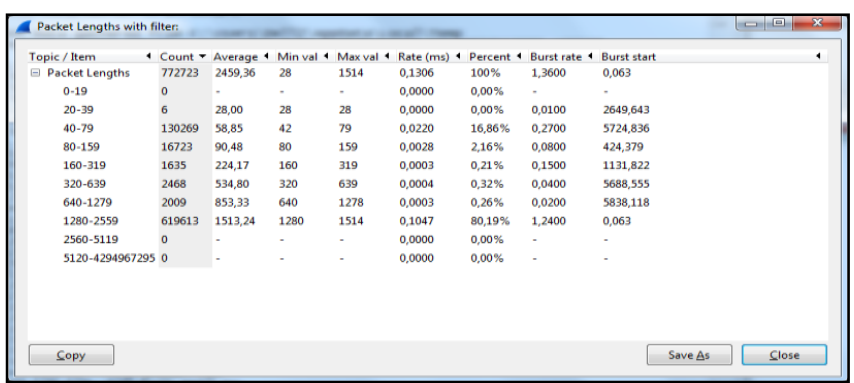

Fig. 10. The results of packets filtering by length

The general information about the interseption session, meaning its beginning, end, amount of packets, average transmission speed is displayed in Comments Summary.

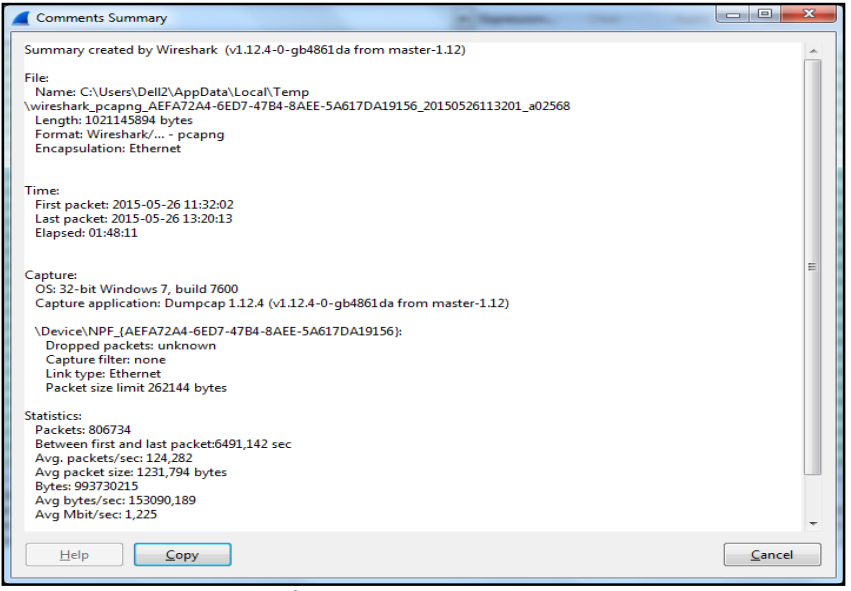

Fig. 11. The general information about interception session

In addition, it is possible to get the quantity of HTTP and IP protocol types, if necessary. It should be done as follows: Lauching Wireshark $\rightarrow$ Wireless network connection $->$ Start $->$ Statistics $->$ HTTP $\rightarrow$ Packet Counter or Lauching Wireshark $\rightarrow$ WWireless network nonnection -> Start -> Statistics -> IP Statistics -> IP Protocol Types accordingly.

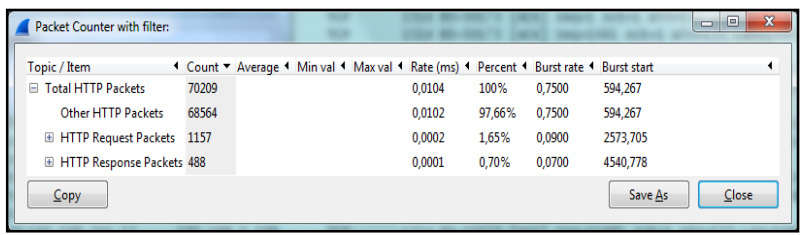

Fig. 12. Quantity of HTTP packets

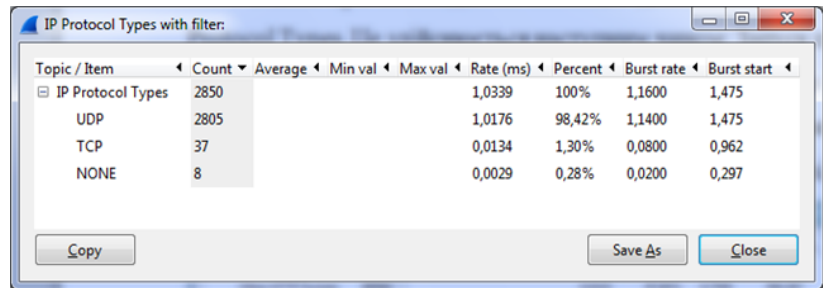

Fig. 13. IP Protocol Types

With the help of network interface, we now chosing the connection in a local network and performing the packet interseption in real time mode. This action includes following steps: Launching Wireshark -> Local network connection -> Start. Illustration of intersepted packets:

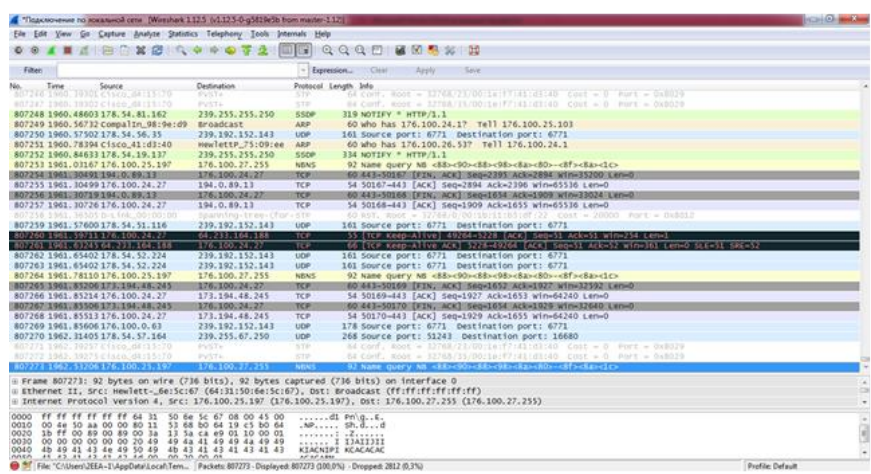

Fig. 14. Intersepted packets

With the use of graphic interface (Launching Wireshark -> Local network connection -> Start -> Statistics -> IO Graph), we can observe the graphical illustration of interepted traffic. 


\begin{tabular}{l}
\hline Wireshark 10 Graphs: Подключение по локальной сети \\
\hline Graph
\end{tabular}

Fig. 15. Graphic illustration of intersepted traffic

With the help of a packet length filter, we receive the quantity of packets of various duration, their percentage, range of minimum and maximum values of packets, etc.

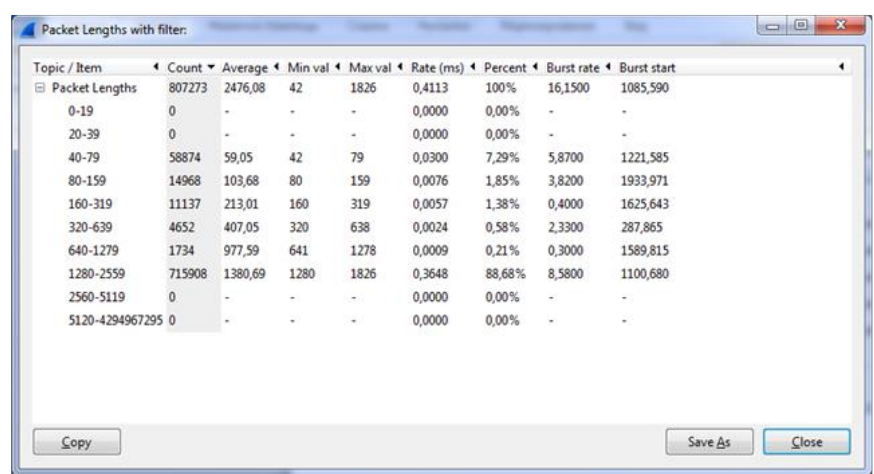

Fig. 16. The results of packets filtering by length

There is a possibility of percentage analysis of different protocols after the data alanysis. To access the protocols hierarchy statistics following steps are needed: Launching Wireshark -> Local network connection -> Start -> Statistics -> Protocol Hierarchy.

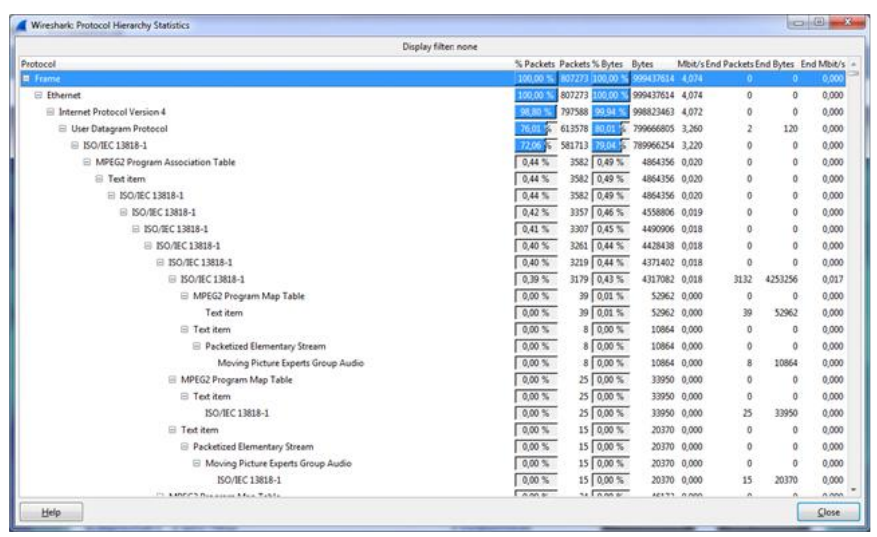

Fig. 17. Protocol hierarchy

In addition, it is possible to get the quantity of HTTP and IP protocol types, if necessary. It should be done as follows: Lauching Wireshark $>$ Wireless network connection $>>$ Start $->$ Statistics $->$ HTTP $\rightarrow>$ Packet Counter or Lauching Wireshark $\rightarrow>$ WWireless network nonnection $>>$ Start $->$ Statistics $>>$ IP Statistics $>>$ IP Protocol Types accordingly.

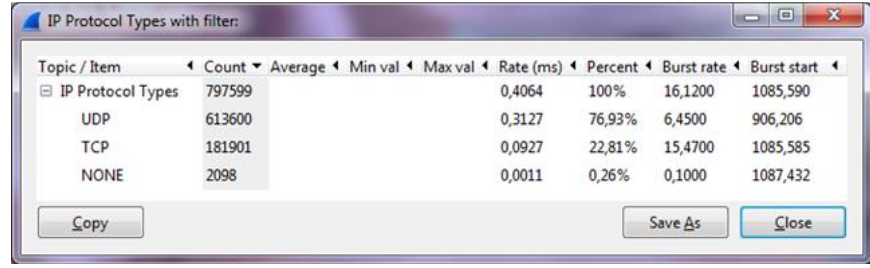

Fig. 18. Quantity of HTTP packets

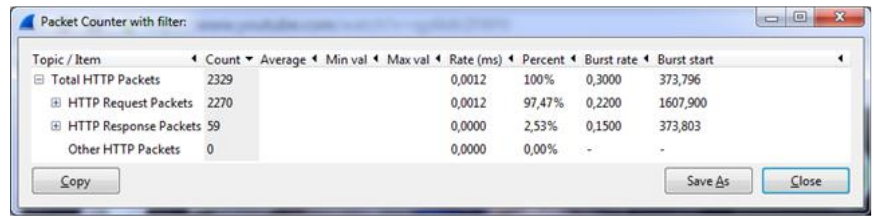

Fig. 19. IP Protocol Types

The general information about the interseption session, meaning its beginning, end, amount of packets, average transmission speed is displayed in Comments Summary.

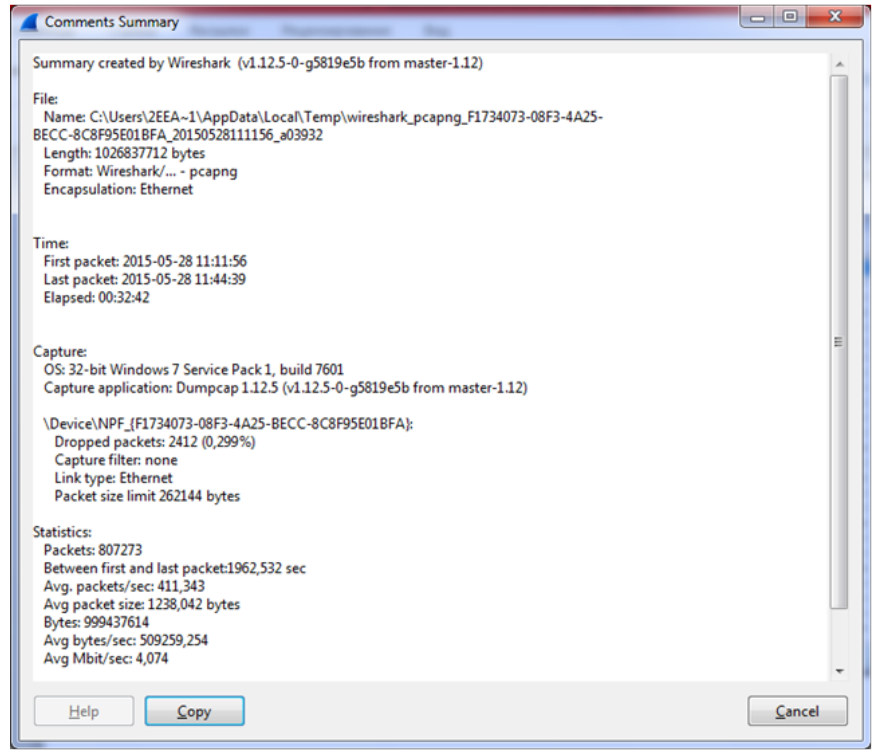

Fig. 20. General information about the interseption seanse

We now compare the quantity of intercepted packets for considered cases and performing the graphical illustration.

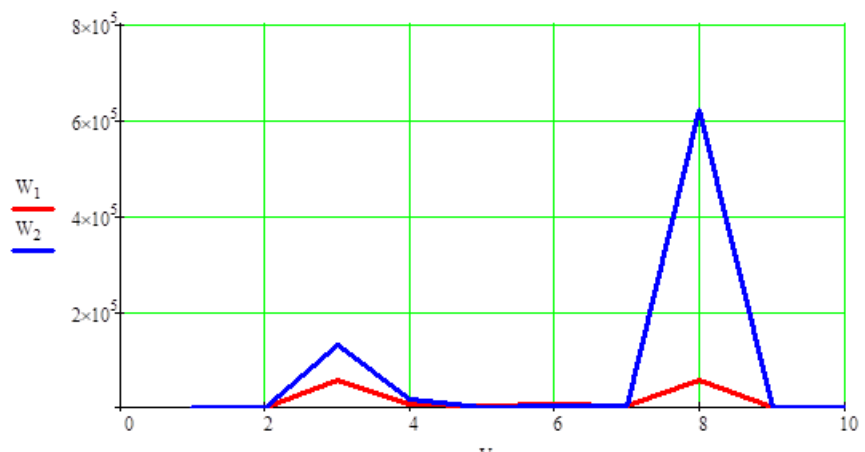

Fig. 21. Compairing the results of filtering packets by length

We now check if the experimentally received flow is self-similar. The Dispersion - time interdependence for the intercepted traffic: 


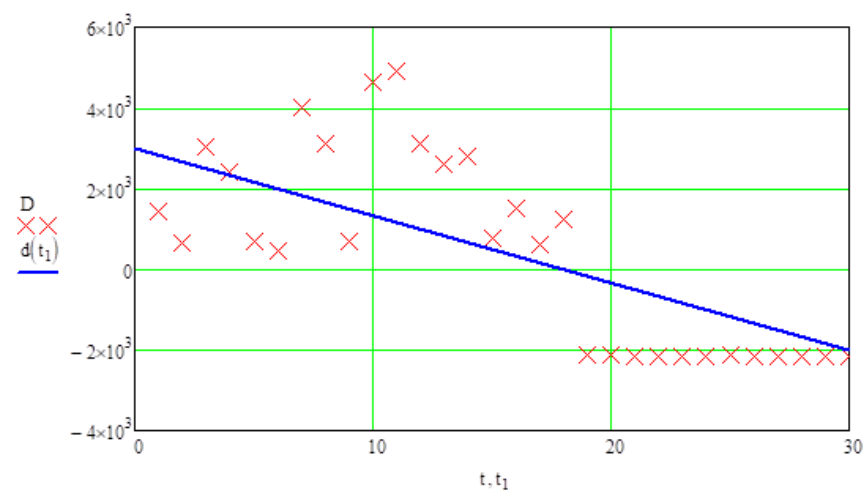

Fig. 22. Dispersion - time interdependence for the intercepted traffic

The reseived slope of line equals. With the help of it we can calculate the self-similarity coefficient $H=1-|\beta|$. The resulting

scope of line equals 0,1687 . It means that the value of Herst parameter is 0,8313 , which is equal to value of Herst parameter for the self-similar traffic $(0,5<H<1)$.

\section{Conclusions}

Traditionally, the self-similarity in the stochastic process is identified by calculation of the Herst $(\mathrm{H})$ parameter value. The fact, that $0.5<H<1$, meaning that Herst parameter is different of

0.5 , is an enough reason to state that the process is self-similar. Not to mention, that the value of a Herst parameter which is close to one, may mean that the process is determined, not random: for a gange of strictly-determined processes, structure is strictly repeated on any scale, which leads to "one" value of Herst parameter. Based on the results, that were received from the experimental research of network perfomance, dispersion - time interdependence for the intercepted traffic and the slope of line $\beta$, we may conclude that the

observed traffic in real-time mode is self-similar by its nature. The results of this paper may be used for the further investigation of network traffic and work on the existing models of network traffic. Furthermore, the adequacy of the description of real is achieved by complexifying the models, combining several models and integration of new parameters. Accordingly, for more complex models, there are higher computing abilities needed or longer time for the generation of traffic realization.

\section{References}

1. O. Sheluhin. Multifractals. Infocommunicational applications, M.: Hotline-Telecom, 2011, $576 \mathrm{p}$.

2. A. Melikov, L. Ponomarenko, V. Paladuk. Teletraffic: Models, methods, optimization, K.: IPK «Polytechnica», 2007,256 p.

3. O. Sheluhin, A Tenyakshev, A. Osin. Modeling of information systems. Study guide, M.: Radiotechnica, 2005, 368 p.

4. A. Privalov, M. Bayeva. Modeling of self-simirlar traffic// News from the Samara science centre of Russian science academy, P. 1041-1046.

5. A. Kostromitskyi. Approaches to self-similar traffic modeling // Eastern-Europe journal of modern technologies, 2010, 4/7 (46), C. 46-49.

6. R. Shyhaliyev. Analysis and classification of network traffic in computer networks // Information technologies problems, 2010. - №2, C. 15-23.

7. E. Dobrovolskyi, O. Nechyporuk. Modeling of the network traffic with the use of context methods // Science works ONAZ named after. O. S. Popov, 2005, №1, P. 24-32.

8. I. Matychyn, V. Onyshchevko. Modeling and analysis of telecommunication systems and networks traffic // Visnyk DUIKT, 2013, №4, P. 20-27.

9. N. Trenogyn, D. E. Sokolov. Fractal features of network traffic in a client-server information system // Vestnyk NII SYVPT, P. 163-172.

10. A. Kostromitsky Network traffic analysis and monitoring tool review, Access mode: http://pi.314159.ru/volotka/volotka1.htm

11. Y. Semenov Network modeling, Access mode: http://citforum.ck.ua/nets/semenov/4/45/modl4517.shtml

Authors

DSc, PhD, docent Marek Aleksander - Institute of Technology,

State University of Applied Sciences in Nowy Sącz, e-mail: aleksandermarek4@gmail.com

PhD Associate Professor Roman Odarchenko - Academic Dept of Telecommunication Systems, National Aviation University (Kyiv, Ukraine)

DSc, Associate Professor Sergiy Gnatyuk - Academic Dept of ITSecurity, National Aviation University (Kyiv, Ukraine)

Mr. Tadeusz Kantor - Institute of Technology State University of Applied Sciences in Nowy Sącz 